\title{
Diálogos entre Bruno Latour e Ulrich Beck: Convergências e divergências
}

\author{
Dialogues between Bruno Latour and Ulrich Beck:
}

Convergences and divergences

Tatiana Gomes Rotondaro*

\begin{abstract}
Resumo: Este texto tem por objetivo expor e refletir sobre o debate entre dois dos principais cientistas sociais da atualidade: Ulrich Beck e Bruno Latour. Contudo, sugiro ainda que esse debate transcende o nível de suas convergências e divergências nos fornecendo indicativos de algumas tendências nas humanidades. Um dos aspectos que pretendo discutir se refere ao que observo como uma "abertura antropológica" das ciências humanas, que de modo algum corresponde a sua antropologização. Argumento que em função da proliferação de crises, pela quais passam as instituições contemporâneas, sociólogos e cientistas políticos tendem a abrir seus esquemas macroexplicativos da realidade social ao escrutínio e à combinação de metodologias antropológicas como meio de encontrar bases para a construção de novos parâmetros que possam balizar projetos políticos normativos inclusivos.
\end{abstract}

Palavras-chave: teoria social; teoria do ator rede (ANT); cosmopolitismo; Ulrich Beck; Bruno Latour

\begin{abstract}
This paper aims to expose and reflect on the debate between remarkable social scientists of our time: Ulrich Beck and Bruno Latour. However, I still suggest that this debate goes beyond the level of their convergences and divergences in providing indicative of some trends in the humanities. One aspect that I intend to discuss refers to what I see as an "anthropological openness" of the human sciences, which in no way corresponds to his anthropologization. I argue that due the proliferation of crises sociologists and political scientists tend to open their macro-explanatory schemes of social scrutiny and the combination of anthropological methodologies as a mean of finding bases for new parameters that can delimit normative political projects.
\end{abstract}

Keywords: social theory; actor network theory (ANT); cosmopolitanism; Ulrich Beck; Bruno Latour

* Doutora em Sociologia pelo Iuperj, professora no departamento de Sociologia da Universidade Federal Fluminense, no Rio de Janeiro, RJ; áreas de pesquisa: teoria sociológica, sociologia ambiental e estudos de ciência, tecnologia e sociedade, especialmente, a análise das biotecnologias, das nanotecnologias e da genômica; <tatiana.rotondaro@hotmail.com>.

\begin{tabular}{|l|l|l|l|l|l|}
\hline Civitas & Porto Alegre & v. 12 & n. 1 & p. 145-160 & jan.-abr. 2012 \\
\hline
\end{tabular}




\section{Introdução}

Questionamentos acerca do grau de autonomia que os indivíduos possuem para conduzir suas ações em sociedade, sobre o quanto esses mesmos são hábeis em construírem as instituições sociais em que vivem, ou em que medida são por elas modelados, se constituem, historicamente, como um dos temas centrais da teoria sociológica, que pode ser observado desde a criação da disciplina, conforme expresso nas obras dos clássicos. Desde os clássicos, diferentes fases e matrizes explicativas nos foram apresentadas visando construir recursos analíticos mais precisos para lidar com essa dicotomia entre agência e estrutura (Anderson, 1984; Alexander, 1987; Domingues, 2001; Corcuff, 2001).

Atualmente, nos deparamos com um contexto em que reina um sentimento de que as pujantes propostas de síntese do final dos anos 1980 e início dos 1990, conforme formuladas por Bourdieu, Giddens, Habermas e Luhmann, estariam dando sinais de esgotamento. Isso ocorre não apenas pelas profundas transformações históricas que temos testemunhado, sobretudo após a queda do muro de Berlim, que nos colocam diariamente desafios políticos, sociais, econômicos e civilizacionais impensados, como por exemplo, a delineação de uma nova reordenação geopolítica do mundo, em função das crises europeia e norte-americana, além de significativos rearranjos dos países emergentes; mas também porque as promessas metodológicas e analíticas, tais como o desafio de coadunar a integração sistêmica com uma integração social, permanecem ainda como um problema a ser resolvido.

Disso decorre que a consolidação de instituições mais ou menos universalizáveis durante a modernidade criou uma sensação, talvez artificial, de que essa 'tendência universalizante' se sustentava por afinidades antropológicas comuns à toda classe de humanos. Porém, a velocidade com que as sociedades vêm se complexificando e, ao mesmo tempo, se diferenciando, tem colocado novas luzes a esses aspectos não solucionados da modernidade, sublinhando os desafios de superá-los de forma ainda mais urgente. Nesse sentido, gostaria de sugerir que temos observado dentro das ciências humanas em geral uma tendência a uma "abertura antropológica", como um recurso para escrutinar o processo de reordenação que ocorre de maneira diferenciada, mas simultânea em todas as sociedades (Beck; Latour; Thévenot etc.). Não se trata, necessariamente, como muitos antropólogos querem fazer crer, de uma antropologização das ciências humanas, mas sim de um recurso para que aspectos reprodutivos da vida social, tidos como cristalizados, possam ser reanalisados de forma a construir uma elaboração explicativa mais ampla dos 
processos sociais, no caso da sociologia, e uma possibilidade de refundação de um 'novo pacto social', no caso da política. Nessa perspectiva, esse texto propõe analisar essa tendência contemporânea, através das obras e do diálogo travado entre dois dos mais expressivos cientistas sociais contemporâneos: Ulrich Beck e Bruno Latour. Pretendo argumentar que embora essa "abertura antropológica" seja uma tendência mais ampla, penso que as soluções, dificuldades e resistências dessa nova tendência de teorização social que se delineiam podem ser amplamente iluminadas através desse debate.

\section{Modernização reflexiva: da sociedade industrial à sociedade de risco}

Dentro de uma matriz marxista, estamos acostumados a ouvir que a história da humanidade poderia ser contada como a história dos sucessivos modos de produção, e que a passagem de um modo de produção para outro ocorreria no momento em que as forças produtivas atingissem o auge de seu desenvolvimento, de tal forma que entrariam em contradição com as relações de produção, provocando a superação do próprio sistema, uma superação das estruturas e estratificações responsáveis pela manutenção do próprio modo de produção. Ainda com base nessa interpretação, qualquer mudança ocorrida na infraestrutura, na base material da sociedade, se expressaria em consequentes transformações na superestrutura - nas instituições sociais que existiam como forma de manutenção e legitimação das relações de produção fundamentais (Marx; Engels, 2000; 1974; Marx, 1978).

Numa perspectiva sintonizada e herdeira dessa lógica de raciocínio da Teoria Crítica da sociedade, Ulrich Beck argumenta que semelhante à organização da sociedade industrial, que nunca existiu somente como sociedade industrial, uma vez que possuía uma parte feudal - da qual se originou - e uma parte industrial, a atual configuração social também é híbrida. Isso porque a modernização do século 19 "dissolveu a esclerosada sociedade agrícola estamental, [...] hoje a modernização dissolve os contornos da sociedade industrial e, na continuidade da modernidade, surge uma outra configuração social" (Beck, 2010, p. 12-13). Vivemos, portanto, segundo Beck, numa transição de uma primeira modernidade para uma segunda modernidade. A primeira modernidade teria sido marcada por uma modernização simples, conforme nos foi narrado pelos clássicos da sociologia - Marx, Weber, Durkheim e Simmel - e essa segunda modernidade, na qual vivemos, seria caracterizada por uma modernização reflexiva, na qual se atingiu um tal nível de desenvolvimento das forças produtivas que tem revolucionado a sociedade industrial, mas (pelo menos ainda) não numa direção emancipatória nos 
termos marxistas. A sociedade industrial, "nos passos leves da normalidade, se despede do palco da história, [...] e não do modo como até hoje havia sido previsto [...]: com um estrondo político (revolução ou eleições democráticas)" (Beck, 2010, p. 13).

Nesse sentido, a organização social, entendida através do padrão de vida coletivo, progresso, controle, pleno emprego e exploração da natureza, que eram típicos da primeira modernidade, estão agora, na segunda modernidade, sendo indeterminados por uma série de processos interligados: globalização, individualização, revolução dos gêneros, subemprego e riscos globais (como as crises ecológicas e a do mercado financeiro). "O real desafio teórico e político desta segunda modernidade está no fato de que a sociedade precisa lidar com a obrigação de responder a todos estes desafios simultaneamente" (Beck, 2000, p. 2-3). Isso porque, se esses processos forem considerados separadamente, tornar-se-á evidente o que eles têm em comum: são todos consequências imprevisíveis da vitória da primeira, simples e linear modernização industrial, baseada sobre os estados-nação.

Em que pese o paralelo que o próprio Beck (2010) traça com a interpretação de Marx da sociedade, cabe ressaltar sua sutil diferença, em função de suas consequências interpretativas. A primeira diferença que se coloca nessa analogia se refere ao fato de que os contornos de uma nova configuração não seriam resultado do fracasso da sociedade industrial, ao contrário, seriam o produto de sua própria modernização bem sucedida, resultado de sua própria concretização. Segundo, é curioso notar como Beck traça uma "equivalência" entre modo de produção e modernidade, o que lhe permite compreender a falência das instituições modernas, ou da superestrutura - numa linguagem clássica, como uma fase da própria sociedade industrial. Dessa forma, qualquer discussão sobre o que a "crise" do sistema representaria, pode ser respondida como um indicativo de uma mudança civilizacional, que não implicaria numa transformação do modo de produção. Uma série de indícios sobre as transformações na base material da sociedade, sobretudo, nas relações entre sociedade e natureza, também está colocada em suas reflexões de forma central, contudo, Beck se desvencilha da implicação que articula a mudança institucional com as transformações da base material.

Além disso, se tomarmos como eixo de análise essa relação entre sociedade e natureza, iremos observar, como nos indica Beck, que a sociedade atual, sobretudo pelo seu avanço tecnológico e científico, alcançou um nível extremamente elevado no desenvolvimento dessas forças produtivas, de tal modo que a sua contradição tem, sobretudo, se expressado na possibilidade de colocar em dúvida a própria manutenção da vida no planeta, em função da ação 
predatória que o modo de produção capitalista tem exercido sobre a utilização dos recursos naturais, ignorando a capacidade regenerativa dos ecossistemas. Teríamos aqui uma outra resposta possível à teleologia marxista: a superação do sistema poderia se dar pelo seu próprio desrespeito à preservação da vida humana (e não-humana), e não necessariamente pelo esgotamento do modo de produção. A essa realidade que nos obriga a conviver com essas possíveis consequências Beck (1992) denomina de Sociedade de Risco.

Beck interpreta a sociedade de risco como um produto de uma modernização reflexiva, na qual a lógica da distribuição de riqueza é progressivamente superposta pela lógica da distribuição de riscos, ou seja, por problemas que atingem a todos indiscriminadamente, ainda que de forma diferenciada, mas dos quais ninguém pode escapar. Exatamente por essa característica estaríamos vivenciando um momento no qual não é mais possível falar em outros. Seria o fim dos "outros", enquanto categoria analítica, pois se tratam de riscos que transcendem os limites estabelecidos pelo estadonação, conforme expressos nas mudanças climáticas globais, com toda sorte de fenômenos que as acompanham como tsumanis, furacões, degelo das calotas polares, aumento da temperatura da Terra, bem como os impactos causados, sobretudo pelas novas tecnologias, como a produção de alimentos transgênicos em larga escala sem controle de contaminação, os riscos de catástrofes nucleares, a crise de recursos energéticos, etc. Cabe observar que na própria formulação da sociedade de risco, ao declarar a necessidade de reconhecermos o fim dos 'outros', Beck já insinua a sua tendência a uma ‘abertura antropológica' que irá se evidenciar mais claramente quando se concretizar sua proposta de cosmopolização das ciências sociais.

\section{Mas, e se jamais tivermos sido modernos?}

Sempre muito criativo e perspicaz, Bruno Latour se insere de forma original na discussão sobre as condições limites da modernidade e do suposto nascimento de uma sociedade pós-moderna.

Bruno Latour se tornou inicialmente reconhecido pelas suas contribuições antropológicas para os estudos de ciência e tecnologia. Contudo, outros fatores inusitados na biografia do autor poderiam nos auxiliar a compreender os futuros desdobramentos em sua carreira. Apesar de seu entusiasmo com o método etnográfico - em função do respeito com que este permitia o estudo de outras culturas -, não escapava à percepção de Latour, devido a sua formação em filosofia, o fato que este método estava baseado em um procedimento científico, baseado em fortes pressupostos, que serviam de suporte para construção de suas narrativas. Foi a partir desta observação que Latour começou a se 
indagar sobre o que se poderia dizer do discurso científico se ele próprio fosse analisado etnologicamente. Tal raciocínio levou-o a concluir, com certo pesar, que a antropologia havia se tornado uma espécie de 'ciência da periferia', uma vez que não sabia mais voltar-se para as questões que estavam no centro das sociedades ocidentais (Latour, 1997). Após esse diagnóstico, Latour iria escrever dois importantes livros para os estudos de ciência e tecnologia, Vida em laboratório (1997) e Ciência em ação (2000), nos quais ele começa a elaborar questionamentos que posteriormente iriam culminar em suas reflexões sobre a própria modernidade.

Em suas primeiras formulações sobre os estudos de ciência e tecnologia, Latour foi amplamente influenciado pelo programa forte, de Bloor (1978), pela exigência de que se investisse na análise do conteúdo do conhecimento produzido, se opondo a uma sociologia do conhecimento centrada apenas na dimensão cognitiva das ciências, com alguns poucos fatores sociais, o que apenas servia como justificativa para que a análise pudesse ser considerada historiográfica ou sociológica. Visando coadunar o conteúdo do conhecimento com os fatores sociais circundantes, Bloor exige que todas as explicações do desenvolvimento científico sejam simétricas, ou seja, que sejam hábeis em "estabelecer uma simetria total de tratamento entre os vencidos da história das ciências e os vencedores" (Latour; Woolgar, 1997, p. 22). Essa ideia de simetria, central ao programa forte, seria apropriada por Latour que planejava estendê-la para outros contextos, como por exemplo, para a análise da relação entre natureza e cultura.

Ao aplicar a análise simétrica à dicotomia ente natureza e cultura, distinção fundante das ciências sociais e da própria organização da própria modernidade, Latour (2000) conclui: "jamais fomos modernos". O autor irá argumentar que questionamentos sobre se estaríamos ainda vivendo na modernidade, numa fase específica desta, ou ainda, se já estaríamos numa pós-modernidade se constituem em uma disputa infundada. Como sabemos, argumenta Latour, a modernidade se organizou em torno de uma necessidade, quase obsessiva, em construir zonas ontológicas distintas do que pertenceria ao reino natural ou ao reino da cultura. Obsessão esta que perpassa praticamente todas as formas de conhecimento que tiveram seu processo de institucionalização com o fim da Idade Média e início da modernidade - aqui com especial atenção ao próprio surgimento das ciências sociais, que se organizaram pela necessidade de explicar a organização cultural das sociedades modernas. Esse exercício sobre o qual a modernidade se esmerou, o de distinguir ontologicamente o que pertence ao reino da natureza ou ao reino da cultura, os humanos e os nãohumanos, é conceitualizado por Latour como purificação. Ocorre que nessa 
tentativa de purificação do mundo acabamos por produzir o seu inverso, ou seja, produzimos de fato translações, o que significa dizer que construímos a proliferação constante de novos híbridos de natureza ou cultura, que se traduzem em novos seres, novos objetos, que são simultaneamente naturais e culturais - isso é mesmo verdade quando observamos a produção de quimeras pelas novas tecnologias. Dessa forma, conclui Latour, o objetivo percorrido para a plena realização da modernidade, a obtenção da máxima purificação ontológica possível, através da dissociação e do estabelecimento de fronteiras claras entre o natural e cultural, nunca se realizou, fazendo com que jamais tenhamos sido modernos de fato.

Nesse sentido, se jamais fomos modernos, como podemos pensar numa modernização reflexiva ou numa re-modernização, como prefere dizer Latour (2003)? E a partir desse questionamento começamos a vislumbrar por onde seguirão algumas das divergências entre Latour e Beck. Enquanto este último está claramente buscando uma solução para os desafios contemporâneos num diálogo contínuo com a tradição sociológica, Latour irá propor uma refundação das ciências sociais, inclusive, da própria sociologia. E justamente por isso, apesar de toda engenhosidade de Latour, não podemos ser ingênuos com relação a essa tese. Uma vez que admitimos que "jamais fomos modernos" estaríamos, ao mesmo, também questionando todo o conhecimento que produzimos durante mais de um século sobre essa modernidade, chegando no limite a inviabilizar a própria autocompreensão que construímos de nós mesmos em termos civilizacionais. De fato, esse é o caminho para o qual Latour aponta, embora seja ele mesmo produto dessa modernidade ocidental. Sua pretensão em reelaborar o cenário acadêmico está sempre presente em suas obras (Latour, 1997; 2000; 2004a/b etc.).

Em função de seu comprometimento com o trabalho empírico, e com a antropologia, embora essa segunda menos explicitamente dita até um determinado momento, Latour em uma entrevista em 2004, declarou que talvez essa tese de nossa não-modernidade não seja totalmente válida, sobretudo nas considerações feitas por ele acerca das sociedades pré-modernas, o que não invalida sua posição de que a ligação básica entre os processos de purificação e translação é que quanto mais nós ignoramos a hibridização, mais multiplicamos a proliferação de híbridos. Continuando em sua perene preocupação em reelaborar uma concepção de Modernidade, Bruno Latour, declarou naquele momento que estava especialmente interessado no trabalho de Ulrich Beck, uma vez que tinha a impressão de este estava fazendo um apelo a uma modernização reflexiva, cujo objetivo seria semelhante ao seu - a libertação da ignorância de uma posição dúbia quanto à realização da modernidade. 
"Eu não estou certo de que minha posição é válida antropologicamente mas ela é válida politicamente, porque, politicamente, é perfeitamente claro que é a dupla cegueira do moderno que impede o que nós chamamos modernidade reflexiva, ou o que eu chamo não-modernidade" (Latour, 2004b, p. 78-79).

Deve ter sido essa declaração que mobilizou Ulrich Beck (2002) a convidar publicamente Bruno Latour à fazer um "teste" de seu empenho em sistematizar conceitualmente a modernização reflexiva através da proposta de uma sociologia cosmopolita, orientada empiricamente.

\section{Quem age no mundo? Ciência, tecnologia no palco da história}

Ao reconhecer a ciência e a tecnologia como responsáveis pelo exercício de purificação de zonas ontológicas naturais e sociais, e colocar esse esforço como parte do "projeto (mal sucedido) da modernidade", em função de seu efeito não intencional que resultou na constante proliferação de híbridos de natureza e cultura, Latour acaba por colocar a própria ciência e a tecnologia como categorias centrais para compreensão das sociedades contemporâneas. De modo semelhante, Beck elege a ciência e a tecnologia, como as instituições centrais e fundantes da modernidade, e que devem ser seguidas se quisermos compreender o processo de implosão das instituições da modernidade. Embora por motivos diferentes, como busquei explicar acima, ambos convergem no diagnóstico de que o referencial analítico que a própria ciência atual nos fornece para analisar a realidade são insuficientes. Nesse contexto, Beck (1992; 1997; 2000; 2004; etc) não nos fala de híbridos, como Latour, mas sim da proliferação de categorias zumbis, ou seja, de conceitos que continuamos a utilizar mesmo após a sua "morte", conceitos tradicionais, da primeira modernidade, mas que não são mais suficientes.

Tomando por base a distinção entre leigos e peritos, ciência e tecnologia assumiram no pensamento de Beck um forte componente político. Numa fase de modernização simples, avalia o autor, a ciência e a tecnologia adquiriram grande legitimação social porque formavam a chave que dava acesso à porta da prosperidade material. Neste período, o objeto dos métodos científicos se direcionava principalmente ao mundo natural "dado", no qual estavam incluídas as pessoas e a sociedade. Mesmo assim, a lógica de desenvolvimento dessa primeira fase da modernidade se baseou em uma cientifização truncada (Beck, 1992, p. 155), cuja explícita separação existente entre os detentores do conhecimento, os peritos, e a população leiga, permitia a imposição dos resultados científicos sobre a esfera pública, sem que estes métodos fossem questionados. 
Essa legitimação começou a ser questionada principalmente porque a ciência e a tecnologia passaram a contribuir significativamente para a proliferação de riscos oriundos da modernização. Em resposta às pressões externas ao âmbito científico, vindas da esfera públicas, começou a surgir um movimento, interno à esfera científica, de autoquestionamento de suas fundações, fazendo com que esta segunda fase fosse baseada em um cientifização completa, na qual se estende o ceticismo científico às fundações inerentes à própria ciência e às consequências de sua aplicação. Nesse sentido, tanto as suas reivindicações de verdade, como de esclarecimento, são desmistificadas. Além dessas pressões externas pode-se ainda encontrar uma parcela, relativamente pequena, de cientistas que também começam a questionar o papel da ciência dada a grande quantidade de novos objetos que emergem em seu desenvolvimento, movimento do qual Beck e Latour também fazem parte. Como consequência desse processo de desmistificação das ciências surge uma importante desmonopolização das reivindicações de conhecimento científico, assim, "a ciência se torna cada vez mais necessária, mas ao mesmo tempo, cada vez menos suficiente para a definição socialmente forçada de verdade" (Beck, 1992, p. 156). Mas, por outro lado, as ciências tornam-se mais diferenciadas gerando um fluxo cada vez maior de resultados condicionais, incertos, às vezes sem sentido e impossíveis de serem avaliados. Essas incertezas produzidas sistematicamente se estendem às relações externas à esfera científica, transformando grupos que são objetos da investigação e os responsáveis pela difusão do conhecimento científico na esfera pública, em co-produtores ativos no processo social de definição do conhecimento. Isso acontece porque as divergências dentro do conhecimento científico fazem com que cada resultado de pesquisa apresentado seja apenas parcialmente aceito (Beck, 1992; Latour, 1997; 2000).

Nas palavras de Beck, nem mesmo as fundações da racionalidade cientifica são poupadas das demandas generalizadas por mudança. Quanto mais claramente situações de conflitos de risco entram na consciência pública maior se torna a pressão para agir contra as incertezas; mas, como mudanças trazem incertezas, a comunidade científica se apropria deste raciocínio para justificar a criação de novos tabus de imutabilidade. A sociedade civil, entretanto, levanta a suspeita de que "constrangimentos objetivos", "efeitos colaterais latentes", que dizem respeito a um "autodinamismo" do desenvolvimento tecnocientífico são eles mesmos manufaturados (Beck, 1992, p. 157).

Aqui, fundamental é perceber que desde o início de suas reflexões Beck está centrado na questão política dos riscos. Em outras palavras, na medida em que eles são industrialmente produzidos, Beck compreende que eles 
também são politicamente reflexivos, uma vez que são produto de decisões. Riscos são produtos das ações e omissões humanas, num contexto de forças produtivas altamente desenvolvidas. Como consequência, os riscos tornam-se motor da autopolitização da modernidade na sociedade industrial, ainda que o conceito, o lugar e o meio da política mudem. Nesse contexto, identifica Beck (1992, 1997), surgem, ao mesmo tempo, um vazio político institucional e um renascimento não institucional do político, uma cultura política que reflete o fracasso da política institucional a partir da ativação de uma subpolítica, que perpassa todos os níveis de organização social, incluindo aqui a imbricação do saber formal com o saber tradicional na busca de novas soluções aos riscos e perigos que enfrentamos. Nesse ponto, vemos a forte confiança depositada por Beck na capacidade e, talvez mesmo, na necessidade de ação política dos indivíduos, como agentes fundamentais na produção da realidade social.

Mas, o que poderíamos dizer sobre a capacidade desses humanos, que se acreditam modernos, se nos engajarmos na proposta de uma não modernidade conforme formulada por Latour? Nada. Ao recorrer novamente à sua proposta de análise simétrica, Latour atribuirá à ação humana o mesmo nível de importância que a ação dos não humanos, preferindo se referir a todos os agentes como actantes, cuja atuação foi sintetizada através de sua formulação da teoria do ator-rede (ANT) (Latour, 1996; 1997).

AANT proposta por Latour se refere a um recurso metodológico que não se limita à análise do ator humano individual, mas estende a palavra ator assim como suas implicações - para as entidades não humanas, que se articulam através de interações que possibilitam e, ao mesmo tempo, se constroem em uma rede. A ideia de rede (réseau) contida nessa proposição se apropria de um forte apelo ontológico, fundamentado numa concepção filosófica monista. Talvez mais correto fosse se referir à ANT como "ontologia do Actante-rizoma" (Mike Lynch, 1993). Nesse sentido, a teoria do ator-rede se refere a um ator que realiza um trabalho, daí a expressão ator-rede. $\mathrm{O}$ ator para a ANT se refere a uma definição semiótica, por isso a avaliação de que seria mais apropriado falar de actantes, isto é, alguma coisa que age, ou cuja atividade é conferida por outrem. Sendo que nessa definição não está implícita nenhuma motivação de atores individuais humanos, nem de humanos em geral. "Um actante pode literalmente ser qualquer coisa, contanto que seja conferido a ele a fonte de uma ação". Não há na ANT nenhum modelo de ator (humano), nem qualquer lista básica de competências que tem que ser estabelecida desde o princípio, porque o humano, o self, e o ator social da teoria social tradicional não estão em sua agenda. O que está na agenda da ANT é a compreensão de quais são as atribuições características de humanos e não humanos (unhuman, non-human, 
inhuman - ou seja, entre os actantes -; as conexões estabelecidas por estes; a distribuição de propriedades entre as entidades; a circulação vinculada por estas atribuições, conexões e distribuições, assim como a transformação destas pelos muitos elementos que circulam na rede (Latour, 1997, p. 5). Resumindo, a ANT diz respeito a uma atividade traçadora de redes (networks), e não a redes traçadas. "Nenhuma rede (net) existe independentemente do próprio ato de traçá-la" e nenhum traço é feito por um ator exterior à rede (net). O foco da ANT não é saber se a rede (net) é uma representação ou uma coisa que poderia ser parte da natureza, da sociedade ou do discurso, mas sim desvendar o que se move na rede e como este movimento é gravado (Latour, 1997).

Como se pode observar, estamos diante uma das divergências fundamentais entre Ulrich Beck e Bruno Latour. Enquanto Beck atribui um papel central à agência humana, uma vez que são as decisões humanas, com sua intencionalidade, que produzem as incertezas e que também as gerencia, deixando claro aqui o confronto entre projetos políticos diferentes, Latour, irá esvaziar essa ação humana de qualquer conteúdo cognitivo relevante, não reconhecendo a validade de projetos humanos conscientemente $\mathrm{e}$ intencionalmente elaborados. Esse tem sido um ponto de sucessivas críticas ao trabalho de Latour, mesmo entre os entusiastas de sua metodologia (Emirbayer; Goodwin, 1994; Pels, Hetherington; Vandenberghe, 2002; Saito, 2011, etc.). Todo esforço de incorporação do outro, apresentado por Beck, e que estou denominando aqui de abertura antropológica, não se expressam como suficientes para Latour. Segundo sua própria avaliação: "o que está em questão entre nós é em que medida nós estamos prontos para absorver as dissidências não apenas sobre a identidade de humanos, mas também a identidade do cosmos em que eles vivem" (Latour, 2004, p. 451). Contudo, apesar dessa divergência fundamental, não raramente vemos pesquisadores engajados com as preocupações políticas de Beck, mas que continuam buscando fazer uma síntese objetiva da obra dos autores, recorrendo à metodologia proposta pela teoria do ator-rede (ANT), de forma bem pragmática (Saito, 2011). Talvez, fosse essa mesma a intenção de Beck (2002) ao convidar Latour para avaliar a validade empírica de suas proposições teóricas. Proposta, aliás, que se tornou relativamente inviável como veremos adiante.

\section{Cosmopolitismo e associações}

Desde a repercussão alcançada pela Sociedade de risco, Beck (1992) reconhece que as ciências sociais enfrentam um duplo desafio: primeiro, a necessidade de recuperarem sua capacidade de compreensão e interpretação do mundo; e, segundo, de se reciclarem efetivamente, submetendo à comprovação 
empírica a atual validade de categorias analíticas canônicas. Com essas preocupações em mente Beck anuncia um programa de pesquisa, inicialmente sobre a teoria da modernização reflexiva (Beck; Bonss; Lau; 2003), e que vai progressivamente se direcionando para os estudos de "cosmopolitização" como um fenômeno empírico.

A cosmopolitização, da qual nos fala Beck $(1999 ; 2002)$ surge a partir da reelaboração de dois conceitos que seriam, em sua avaliação, chaves para interpretar a atual fase da modernidade: globalização e cosmopolitização. Visando clarificar sua compreensão de globalização, Beck inicia a construção de seus argumentos pela ideia relativamente bem difundida de que nesse início do século 21 vivemos um tipo de organização social que não pode ser interpretada de forma linear, de tal modo que a condição humana não pode ser compreendida nacionalmente ou localmente, mas apenas globalmente. Tratase de uma globalização dialética na qual local e global não existem enquanto polaridades culturais, mas apenas enquanto princípios mutuamente implicados e combinados. A compreensão de que esse processo de globalização altera a qualidade do político e do social dentro dos estados nacionais, é o que caracteriza a cosmopolitização. Cosmopolitização significa, nas palavras de Beck (2002, p. 17), um tipo de globalização interna, uma globalização que emerge das sociedades nacionais, isso porque questões e preocupações globais estão se tornando parte da vida cotidiana, das experiências locais e do 'mundo da vida moral' das pessoas, alterando suas consciências e identidades significativamente. Apesar das críticas questionando, sobretudo, a real diferença entre cosmopolitismo e globalização (Calhon, 2003; Roudometof, 2005); podemos observar que a proposta de estudos empíricos sobre cosmopolitização logrou um sucesso que não pode ser desconsiderado (Beck; Beck-Gernsheim, 2009; Philips; Smith, 2008 etc.).

Em termos analíticos, a cosmopolitização proposta por Beck se estender a uma cosmopolitização da própria ciência, cuja principal característica repousa numa 'imaginação dialógica', significando o choque de culturas e racionalidades dentro da própria vida, ou seja, uma forma de lidar com o 'outro internalizado'. "A imaginação dialógica corresponde à coexistência de modos rivais de vida na experiência individual, a interpenetração de várias culturas". A perspectiva nacional seria uma imaginação monológica, que exclui a alteridade. Nesse sentido, a perspectiva cosmopolita representaria uma imaginação alternativa que precisaria estar pronta para dois tipos de aberturas básicas: à alteridade externa e interna, que se traduzem numa abertura (a) ao mundo natural, (b) uma abertura aos estrangeiros, às outras civilizações, e aqui talvez valesse a ressalva de que uma abertura às culturas estrangeiras 
parece mais bem aceita do que uma abertura às pessoas estrangeiras, e (c) uma abertura às contingências do futuro. Dito de outra forma, "o que uma 'cosmo-lógica' significa é seu pensar e viver em termos de oposições inclusivas" (Beck, 2002, p. 18-19).

Apesar do esforço apresentado por Beck em se engajar num programa de pesquisa empírico, salta aos olhos de Latour (2004), quanto de alguns analistas (Delanty, 2009; Saito, 2011; Gross, 2009) o forte componente normativo de suas proposições. Aproveitando a oportunidade de diálogo oferecida por Beck, Latour se contrapõe às teses do colega reafirmar sua agenda de pesquisa tanto teórica, quanto metodológica, disciplinar e política (ainda que esta última seja mais claramente visível num nível de política acadêmica institucional), buscando explicitar, quando não aprofundar, as divergências entre eles. Bruno Latour (2004) se coloca duramente contra Beck em sua proposta de cosmopolitização, deixando clara sua pouca disposição em fundir seus respectivos programas pesquisa.

Beck (2005) contra argumenta que os aspectos da cosmopolitização que Latour (2004) classifica como "normativos" existem porque, apesar de seu trabalho analítico e de seus esforços prospectivos do social, existe também em suas reflexões um engajamento com as deliberações políticas que a não compreensão do ritmo de transformação do mundo pode ocasionar. Isso porque Beck continua comprometido, ainda que de forma mais ou menos implícita, com uma perspectiva realista voltada para práxis social. Latour acusa Beck de construir uma visão limitada de cosmopolítica, etnocêntrica, baseada em valores da cultura ocidental, que se expressa não apenas no olhar sobre o outro, mas também sobre olhar dirigido ao mundo em que esse outro vive. ${ }^{1}$ Isso acontece, argumenta Latour, porque Beck ainda está influenciado por um humanismo que se sustenta pela crença na razão, na existência de num agente racional, capaz de perseguir seus objetivos. E na crença de que a ciência é capaz de conhecer $o$ cosmo, cuja existência e solidez poderão escorar todos os esforços para se construir uma metrópole-mundo na qual todos estarão felizes em ser cidadãos.

Não podemos deixar de observar que a crítica de Latour (2004) ao cosmopolitismo e, sobretudo, à cosmopolítica de Beck, está diretamente associada a sua pretensão de estender a sua influência para a sociologia, reafirmando as concepções de actante e de associação, em oposição às

\footnotetext{
1 Curioso observar que para fugir de uma possível acusação de etnocentrismo, visto que estamos diante do confronto de duas perspectivas europeias, Latour (2004) irá se refugiar no perspectivismo de Eduardo Viveiros de Castro (2004), aludindo à visão dos ameríndios que acreditam existir apenas uma cultura e muitas naturezas, em contraposição à visão ocidental hegemônica acostumada a pensar em uma única natureza, permeada por diferentes culturas.
} 
clássicas concepções de indivíduo e sociedade, respectivamente. Nessa nova nomenclatura, conforme vimos acima, os actantes compreenderiam todas as unidades físicas do mundo como potenciais agentes no processo de associação do mundo no movimento de traçar rede, ou seja, no movimento de construir as redes de interação que comporiam um cosmos. Inspirando-se em Gabriel Tarde, Latour (2004) argumenta que de fato a sociedade sempre significou uma associação e que nunca se limitou apenas aos humanos.

No debate com Beck, Latour sugere outra perspectiva de análise sociológica, na qual se reconhece como filiado. Trata-se de uma linha de pensamento que poderia ser traçada com Tarde - Garfinkel - ANT. E ao fazê-lo, Latour não se intimida em propor uma releitura da história das ciências sociais, na qual poderíamos reconstruir um consenso acadêmico que atribuiria a paternidade da sociologia não à Durkheim, mas sim a Gabriel Tarde. Essa proposta analítica critica a abstração contida na categoria sociedade, e pretende compreender as interações sociais e a própria construção coletiva dessas interações a partir da categoria associação. Essa valorização de análise das relações sociais a partir de uma perspectiva micro se aprofunda através da menção feita à etnometodologia de Garfinkel.

Contudo, se Latour não estivesse tão preocupado em assegurar à tradição francesa a primazia sobre a análise do social, ele poderia ter recorrido a Simmel, que também prefere privilegiar as associações estabelecidas pelas interações. De fato, se voltarmos ao texto O problema da Sociologia, redigido por Simmel (1983), nos depararemos com as dificuldades, que este já havia enunciado, em lidar com o caráter dual que a interpretação do social possui. Essa dualidade se expressa na obra de Simmel a partir da oposição entre forma e conteúdo, sendo a forma algo mais estrutural, resultado da cristalização de interações de alguma forma institucionalizadas, enquanto o conteúdo seria preenchido pelas interações oriundas das associações no mundo da vida. Em que pese a conhecida opção de Simmel por se aprofundar nas análises micro, o problema da interação micro-macro por ele proposto ainda não foi superado e de alguma forma e é justamente por esse motivo que alguns cientistas sociais se sentem tentados a buscar a superação da tragédia da modernidade através de uma possível síntese Latour-Beck.

\section{Referências}

ADAM, Bárbara; BECK,Ulrich; VAN LOON, Joos. The risk society and beyondCritical issues for social theory. London: Sage Publications Ltd, 2000.

ALEXANDER, Jeffrey C. O novo movimento teórico. Revista Brasileira de Ciências Sociais, São Paulo, v. 4, n. 2, p. 6-28, 1987. 
ANDERSON, Perry. A crise da crise do marxismo. São Paulo: Brasiliense, 1984.

BECK, Ulrich. Risk Society: towards a new modernity. London: Sage, 1992.

. O que é globalização? Equívocos do globalismo respostas à globalização. São Paulo: Paz e Terra, 1999.

. World risk society. Cambridge: Polity Press, 2000.

. The cosmopolitan society and its enemies. Theory, Culture \& Society, Nottingham, v. 19, n. 1-2, p. 17-44, Apr. 2002.

. The truth of others: a cosmopolitan approach. Common Knowledge, RamatGan, v. 10, n. 3, p. 430-449, Fall 2004.

Neither order nor peace: a response to Bruno Latour. Common Knowledge, Ramat-Gan, v. 11, n. 1, p. 1-7, Winter 2005.

Sociedade de risco: rumo a uma outra modernidade. São Paulo: Ed. 34, 2010.

BECK, U.; BECK-GERNSHEIM, E. Global generations and the trap of methodological nationalism: for a cosmopolitan turn in the sociology of youth and globalization. European Sociological Rewiew, Nova Iorque, v. 25, n. 1, p. 25-36, Feb. 2009.

BECK, U.; BONNS, W.; LAU, C. The theory of reflexive modernization: problematic, hypotheses and research program. Theory, culture \& society, Nottingham, n. 20(2), p. 1-33, 2003.

BECK, U; WOLFGANG, B; CHRISTOPH, L. The theory of reflexive modernization: problematic, hypotheses and research programme. Theory, culture \& society, Nottingham, v. 20, n. 2, p. 1-33, Apr. 2003.

BLOOR, David. "Polyhedra and the abominations of Leviticus", British Journal for the History of Sciences, n. 11, p. 245-272, 1978.

CALHOUN, Craig. The class consciousness of frequent travellers: towards a critique of actually existing cosmopolitanism. In: ARCHIBUGI, Daniele (org.) Debating Cosmopolitics. London: Verso, 2003, p. 86-116.

CORCUFF, P. As Novas sociologias: construções da realidade social. Bauru, Edusc, 2001.

DELANTY, Gerard. The cosmopolitan imagination: the renewal of critical social theory. Cambridge: Cambridge University Press, 2009.

DOMINGUES, José Maurício. Teorias sociológicas no século XX. Rio de Janeiro: Civilização Brasileira, 2001.

EMIRBAYER, Mustafa; GOODWIN, Jeff. Network analysis, culture and the problem of agency. American Journal of Sociology, Chicago, v. 99, n. 6, p. 1411-1454, May 1994.

GIDDENS, A.; BECK, U.; LASH, S. Modernização reflexiva: política, tradição e estética na ordem social moderna. São Paulo: Editora da Unesp, 1995.

GROSS, Neil. A pragmatist theory of social mechanism. American Sociological Rewiew, Nashville, v. 74, p. 358-379, June 2009.

LATOUR, Bruno; WOOLGAR, Steve. A vida de laboratório: a produção dos fatos científicos. Rio de Janeiro: Relume Dumará, 1997 [1979]. 
LATOUR, Bruno. On interobjectivity. Mind, Culture, and Activity, Philadelphia, v. 3, n. 4, p. 228-245, 1996.

. Ciência em Ação: como seguir cientistas e engenheiros sociedade afora. São Paulo: Ed. Unesp, 2000 [1987].

Jamais fomos modernos. São Paulo: Editora 34, 2000 [1991].

. Morality and technology: the end of the means. Theory, culture \& society, Nottingham, v. 19, n. 5-6, p. 247-260, Dic. 2002.

. Is re-modernization occurring - and if so, how to prove it? A commentary on Ulrich Beck. Theory, culture \& society, Nottingham, v. 20, n. 2, p. 35-48, Apr. 2003.

Whose cosmos, which cosmopolitics? Comments on the peace terms of Ulrich Beck. Common Knowledge, Ramat-Gan, v. 10, n. 3, p. 450-462, Fall 2004a.

Bruno Latour: The social as association. In: GANE, Nicholas. The future of social theory. London: Continuum, 2004b, p. 77-90.

LYNCH, Michael. Scientific practice and ordinary action: ethnomethodology and social studi of science. New York: Cambridge University Press, 1993.

MARX, Karl; ENGELS, F. O manifesto do partido comunista. São Paulo: Martin Claret, 2000 (Coleção: A obra-prima de cada autor).

. Para a crítica da economia política: o método da economia política (Parte 3). São Paulo: Abril Cultural, 1978, p.116-132. (Coleção: Os Pensadores).

MARX, Karl; ENGELS, Friedrich. A ideologia alemã, v. 1, São Paulo: Martins Fontes, 1974 [1846], p. 15-99.

PHILLIPS, Timothy; PHILIP, Smith. Cosmopolitan beliefs and cosmopolitan practices: an empirical investigation. Journal of Sociology, n. 44, p. 391-399, Dec. 2008.

PELS, Dick; HETHERINGTON, Kevin; VANDENBERGHE, Frederic. The status of the object: performances, mediations, and techniques. Theory, culture \& society, Nottingham, v. 19, n. 5-6, p.1-21, Dec. 2002.

ROUDOMETOF, Victor. Transnationalism, cosmopolitanism and globalization. Current Sociology, Hyderabad, v. 53, n. 1, p. 113-135, Jan. 2005.

SAITO, Hiro. An actor-network theory of cosmopolitanism. Sociological Theory, v. 29, n. 2, p. 124-149, June 2011.

SIMMEL, G. O problema da sociologia. In: Simmel - Coleção Grandes Cientistas Sociais, v. 34 (org. E. de Moraes Filho), São Paulo: Ática, 1983.

VIVEIROS DE CASTRO, Eduardo. Exchanging perspectives: the transformation of objects into subjects in Amerindian ontologies. Common Knowledge, Ramat-Gan, v. 10, n. 3, p. 463-484, Fall 2004. 